\section{Clinical precision}

\section{W. F. Bynum enjoys a history of three revolutionary moments in health care.}

$\mathrm{H}$ arvard physiologist Lawrence Henderson once remarked that at some time between 1900 and 1912, a random patient with a random disease, choosing a physician at random, had for the first time in history a better than 50:50 chance of profiting from the encounter.

Henderson's spread bet is not quoted in The Making of Modern Medicine, but it concurs with historian Michael Bliss's take on how, when and where clinical medicine became modern. In this slim volume, based on his 2008 Joanne Goodman lecture series at the University of Western Ontario in Canada, Bliss offers three case studies that chart the leap in physicians' capacity to deal with disease at the start of the twentieth century. Health care was revolutionized by advances in disease prevention, surgery and drug treatments that allowed management of chronic afflictions. Bliss's measured evaluation of the strengths and weaknesses of modern medicine is persuasive and clear.

His first case study is a smallpox epidemic in Montreal, Quebec, in 1885, which sickened more than 20,000 people and killed about 5,000. It could have been prevented: vaccination was almost a century old, and the dynamics of smallpox spread were well understood. But anti-vaccination sentiment was rife. Bliss describes how social factors led to the outbreak being met with a mix of fatalism and ignorance. Most of the victims were children who were poor, French-speaking and Catholic. Their religious leaders failed them: inoculation was viewed as an affront

to divine providence and an intrusion of the state on a helpless citizenry. Two uneducated physicians led the resistance, telling parents that the removal of children to the quarantine hospital was a death sentence. As a result, infected children were kept in the community and became sources of further spread.

It took ten months for the epidemic to burn itself out. Many role model. He is still revered as such.

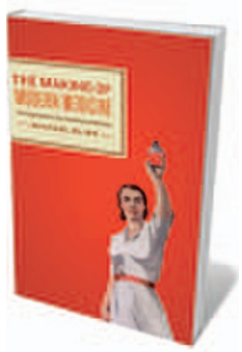

The Making of Modern Medicine: Turning Points in the Treatment of Disease MICHAEL BLISS University of Toronto Press: $2010.112 \mathrm{pp}$. Can $\$ 21.95$ religious leaders maintained that the episode was an act of God sent to a sinful people. But, Bliss explains, most medical observers and liberal journalists at the time recognized it as a catastrophe that should never have happened, caused by antiquated values that were being supplanted by the new creed of science.

Spearheading that scientific approach was the Johns Hopkins School of Medicine in Baltimore, Maryland, the beginnings of which Bliss relates in his second case study. Its first professor of medicine was William Osler, who had left McGill University in Montreal in 1884 - a year before the epidemic - and moved to Johns Hopkins in 1889 after a spell at the University of Pennsylvania in Philadelphia. Osler excelled as a teacher and medical

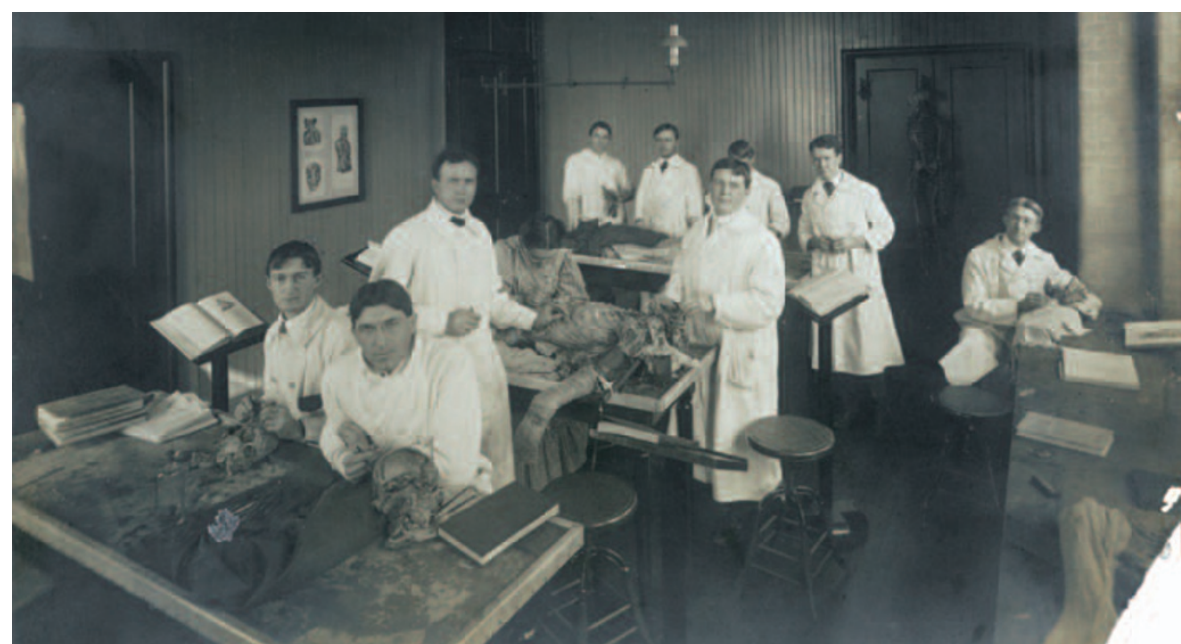

The Johns Hopkins School of Medicine, founded in 1893, pioneered the scientific method in health care.
The foundation of the Johns Hopkins School was a turning point in American medicine: it demanded that its students had a sound educational grounding, and provided both the facilities and the directive for its staff to be at the forefront of research as well as teaching. Its excellence was recognized in a gold-standard award from educational reformer Abraham Flexner, whose famous reports on the condition of medical education in North America in 1910 and in Europe in 1912 pulled no punches.

Osler was the institution's star, but Bliss concentrates on his surgical colleague, Harvey Cushing, as the most significant innovator. Cushing pioneered modern neurosurgery, creating the field almost singlehandedly. He arrived at Johns Hopkins as a resident under the school's founding professor of surgery, William Halsted. Bliss explains that much of the therapeutic power of medicine in those days stemmed from surgery, a point that Osler also acknowledged. Surgeons could cure appendicitis, gall or kidney stones and other conditions that physicians could merely manage. Cushing could even operate successfully on the brain. Teachers and students at Johns Hopkins knew they were at the forefront of a medical revolution.

The decades before and after 1900 witnessed several medical innovations, including aspirin. But nothing captured the headlines like Bliss's third case study: the extraction of insulin in 1921 by Frederick Banting, Charles Best and James Collip in J. J. R. McLeod's lab at the University of Toronto. Louis Pasteur's rabies vaccine in the 1880 s and Wilhelm Röntgen's discovery of X-rays in 1895 were comparable media events. But the dramatic pictures of emaciated children on the verge of death suddenly putting on weight after injections of insulin seemed almost miraculous.

Insulin did not cure type 1 diabetes, but it transformed an acute, fatal disease into a chronic one compatible with many years of life. The parallels between the treatment of type 1 diabetes in the 1920s and the treatment of HIV in our own time are striking.

We should be grateful that many diseases can now be managed. Yet Bliss reflects that the gratitude of people receiving medical treatment, as enjoyed by physicians half a century ago, has collapsed. He attributes this to a misplaced faith in medicine in a secular society. The fatalism of the Montreal poor has been replaced by an ardent expectation that medical science can solve the problems of the human condition. As a result, more of us may empathize with the poet Alexander Pope's sober analysis from more than two centuries ago: “This long disease, my life." -

W. F. Bynum is emeritus professor of the history of medicine at University College London, UK. e-mail:w.bynum@ucl.ac.uk 